\title{
POR QUE CONHECER METODOLOGIA DE PESQUISA
}

WITT, A. - Por que conhecer metodologia de pesquisa. Rev. Esc. Enf. USP, 10(3):340-348, 1976.

São abordadas as razões da importância do conhecimento de metodologia de pesquisa na atualidade, por profissionais de enfermagem; a atenção é focalizada na utilização, execução e administração de pesquisas, tendo em vista o desenvolvimento da enfermagem como ciência.

\section{CONSIDERAÇOES GERAIS}

O termo pesquisa é usado freqüentemente com conotações várias mas que refletem, de modo geral, a idéia de que esta corresponde a uma atividade sistemática, realizada com o propósito de serem obtidos conhecimentos mais avançados.

A definição de pesquisa em enfermagem, por sua vez, tem sido discutida por vários autores, havendo os que fazem distinção entre pesquisas que tem por fim o estudo problemas de enfermagem e as que possuem como centro de atenção a profissão em si mesmo; a distinção refere-se pois ao objeto de investigação, não havendo diferença significante metodológica e/ou técnica.

Não nos deteremos nessas questões ligadas diretamente à conceituação do significado de pesquisa, mas apenas nas razões da valorização do treinamento dos profissionais de enfermagem, em metodologia científica.

- Professor Livre Docente do Departamento de Prática de Saúde Pública da Faculdade de Saúde Pública - USP. 
Que o entendimento e uso de um processo metodológico de investigação é importante por parte dos profissionais em foco fica evidente nas constatações de RINEHART (9), para quem há um crescimento anual da necessidade de interpretações de resultados de pesquisa, por parte dos profissionais de enfermagem.

Aliás, nas sociedades atuais, a investigação científica ocupa um lugar de destaque em qualquer programa racional. A capacidade de raciocinar validamente, como qualquer outra, conforme já salientado por PURCHET (8), desenvolve-se pelo exercício; mas esse exercício, sem dúvida, exige um conhecimento adequado prévio.

A enfermagem atualmente tem desenvolvido um grande número de pesquisas, que refletem exercícios em investigação, dando a sua contribuição não só para solidificar a ciência, base da profissão, mas também para o progresso da sociedade; oportuno é lembrarem-se aqui das palavras de HORTA (6) que dizem ser a pesquisa uma das funções sociais da enfermagem, o que por si só evidencia o valor de realização de pesquisas.

SCHLOTFELD (10), por sua vez, observou que a enfermagem está historicamente relacionada com a pesquisa, embora o treinamento em metodologia seja relativamente recente; assim, exceto exceções, estudos significativos em termos de metodologia científica foram realizados somente nas duas últimas décadas.

Essa situação pode levar à suspeita de que muitos trabalhos são deficientes, requerendo cuidado a aplicação dos resultados. Evidentemente, se considerarmos a enfermagem como o exercício de uma profissão baseada em resultados de investigação, estes precisam ser corretos; e a profissão será tanto mais aprimorada quanto mais rigorosas forem as pesquisas nas quais se baseia; para tanto o conhecimento de metodologia científica é indispensável.

\section{O USO DE RESULTADOS DE PESQUISAS}

E evidente que nem todos os enfermeiros serão basicamente pesquisadores; porém, praticamente todos os situados em posições hierárquicas médias e altas utilizam-se de resultados de pesquisa para tomada de decisões referentes a práticas de enfermagem, administração ou ensino. 
O conhecimento de metodologia de pesquisa, nesses casos, é importante porque permite identificar o processo de investigação seguido, bem como avaliar os resultados encontrados.

O saber ler e interpretar relatórios de pesquisa já foi mesmo considerado uma das 12 atividades esperadas em relação à investigação, por parte de um profissional de enfermagem. $O$ preparo em metodologia de pesquisa teria, então, a sua justificativa no fato de tornar $o$ enfermeiro um leitor crítico de investigações (10), permitindo-lhe julgar o que é pertinente e aceitável, em termos de aplicação dos resultados.

Essa avaliação crítica é necessária porque, infelizmente, ocorrem publicações de trabalhos precários; acreditamos que as limitações dos mesmos devam-se, entre outros, ao fato da falta de treinamento em investigações, também pode haver interferência da "incapacidade treinada”, do autor, isto é, ao fato de ele não perceber imprecisões, por estar demasiadamente envolvido no problema.

Convém lembrar que nem todos os resultados de pesquisa devem ser julgados por um mesmo prisma ou com a mesma rigidez, isto porque, por exemplo, um assunto já bastante estudado teoricamente deve apresentar resultados mais precisos e mais completos que outros cujo corpo de conhecimentos ainda é precário, exigindo a utilização eventual dos resultados e maior cautela.

Outros elementos ainda constituem indicadores analíticos de relatórios de investigação como: o tipo da pesquisa, o grau de validade requerido dos resultados quantitativos, o tempo percorrido entre a obtenção e a publicação ou leitura dos dados, etc.

Em resumo, o conhecer metodologia de pesquisa é importante para quem lança mão de resultados de investigações porque possibilita: a) entendimento perfeito das informações; b) correta interpretação dos dados; c) discussão dos resultados, se necessário; d) utilização segura dos dados; e e) tomada de decisões mais acertadas.

\section{O ENFERMEIRO COMO PESQUISADOR}

Como já observamos, é tendência atual a realização de pesquisas por enfermeiros. Essa atividade tem finalidades diversificadas, co- 
mo: publicações, acesso profissional, seminários, preparação acadêmica, concursos, etc.

Os citados profissionais participam de pesquisas de várias formas: como auxiliares, pesquisadores principais, membros, assessores de equipe, administradores.

E oportuno lembrar a opinião de BAEZ (2): para ele, fazer uma investigação não quer dizer sempre que uma só pessoa deva fazê-la integralmente. Isto porque o saber é hoje muito vasto, de modo que é impossível um só indivíduo dominar todas as disciplinas envolvidas, mas participar de uma investigação é também investigar, ou seja, produzir.

A tendência mencionada para produzir pesquisas é particularmente importante, pois nenhum profissional pode basear as suas atividades em hábitos; por extensão, poder-se-ia dizer que todo enfermeiro deveria ser um pesquisador em maior ou menor escala.

O desenvolvimento de pesquisas liga-se a várias especialidades da enfermagem e ainda a disciplinas com elas correlacionadas. Uma crítica que tem sido feita freqüentemente aos enfermeiros é que as suas pesquisas se centralizam, com freqüência descomunal, em problemas que envolvem grande número de variáveis de disciplinas afins e enfermagem, sendo dada pouca atenção aos problemas específicos de enfermagem. Em posição intermediária de interesse, colocam-se as investigações que focalizam problemas de educação e práticas administrativas; portanto, o desenvolvimento de pesquisas no campo de enfermagem, estaria pecando pela inadequação da seleção de objetivos, que corresponde a uma das fases do processo de pesquisa.

Cada uma das fases de pesquisa é uma fonte potencial de imprecisão. Faz-se necessário antecipar a previsão dos erros para minimizar os seus efeitos; isto requer conhecimento de metodologia de pesquisa e se aplica à própria seleção adequada do objeto de pesquisa, atrás comentada, assim como a escolha das variáveis para estudo deveria, preferencialmente, enfocar ângulos próprios da enfermagem ligados a problemas, sendo outras sẹlecionadas mais a título de subsídios. Há necessidade de serem conhecidos os princípios metodológicos de avaliação das variáveis que farão parte de um dado estudo. 
Mas convém lembrar LANCASTER (7) para quem pesquisa corresponde a um modo de pensar e não a um simples agrupamento de técnicas adquiridas em cursos; requer uma abordagem crítica do conhecimento e habilidade para formular questões relevantes. Portanto, o indivíduo que realiza pesquisa deveria possuir uma estrutura peculiar. Além de concordarmos com o fato de que pesquisa não é um simples agrupamento de técnicas, salientamos, adicionalmente, que a escolha de técnica mais adequada é uma decisão inerente ao processo de pesquisa, que requer conhecimentos metodológicos. Sendo a tomada de decisões uma constante nas várias etapas do processo de pesquisa e correspondendo a decisão à escolha de uma alternativa de ação entre várias, estas alternativas devem ser conhecidas; assim, por exemplo, na fase do planejamento da coleta dos dados é preciso conhecer quais os métodos existentes, bem como os pontos negativos e positivos de cada um deles em relação às demais fases, para que seja possivel a escolha da alternativa que oferece menor probabilidade de erro, num dado estudo.

Com base em nossa experiência e em observações do meio, somos de parecer que os centros de interesse dos enfermeiros, em termos de produção de pesquisa, abrangem 4 áreas, relacionadas a:

1) problemas de natureza clínica e/ou cirúrgica, com investigações, por exemplo, associando variações fisiológicas e técnicas de trabalho, efeitos de procedimentos de enfermagem novos ou simplificados, comparação de resultados decorrentes de aplicação de técnicas diferentes, etc.

2) problemas não diretamente ligados ao campo da enfermagem, mas que são, em grande parte, passíveis de controle por estes profissionais, na prática diária; constituem exemplos o estudo de variáveis sociológicas e psicológicas associadas a efeitos fisiológicos, relação entre tensão pré-operatória e tipo de comunicação com o pessoal de enfermagem, etc.

3) problemas ligados ao curso de enfermagem tais como: demanda dos cursos, adaptação do conteúdo às necessidades sentidas, adequação de estágios, avaliação de programas educatịvos, eficácia de recursos audiovisuais e observação direta, etc.

4) problemas de natureza institucional e administrativa ligados aos papéis e funções organizacionais dos profissionais de enfer- 
magem; constituem exemplos as pesquisas para análise do poder coordenador da enfermagem nas Instituições hospitalares, grau de delegação de responsabilidade dos médicos obstetras para enfermeiras obstetrizes, conhecimento e utilização do potencial profissional especializado da enfermagem.

Esses problemas, base de pesquisas cuja solução é pretendida, necessitam ser colocados em quadros de referência metodológica apropriados para que se obtenha resultados corretos; a apresentação dos temas mais pesquisados em quatro grupos, heterogêneos entre si, leva à suposição de que há uma classificação tipológica de pesquisa. De fato, de acordo com o processo de estudo, as pesquisas geralmente são classificadas em 6 tipos: estrutural, histórico, comparativo, funcionalista, estatístico e monográfico (1), correspondendo a cada uma das modalidades procedimentos próprios, o que por si só evidencia ser necessário o conhecimento de metodologia de pesquisa por parte de quem elabora um plano de investigação.

\section{PROBLEMATICA DA ADMINISTRAÇÃO DE PESQUISAS}

Não pode ser esquecido que a realização de uma pesquisa é uma combinação de decisões organizacionais e técnicas, exigindo, pois, uma administração que não se restringe ao planejamento: abrange a totalidade do processo de uma investigação.

Portanto, o problema do planejamento em si mesmo não é a única barreira ao sucesso da pesquisa; como diz GARO (5), um dos grandes obstáculos é o contexto organizacional ou interorganizacional. Também não podem ser menosprezadas as dificuldades relativas à população, seja ela coletadora de dados, analista ou fornecedora de informações.

Assim, a pesquisa científica pode ser vista como um processo de resolver problemas, sendo que as decisões, de acordo com DOBY (4), representam um compromisso de trabalho entre as exigências rigorosas do método científico e as condições realísticas de recursos existentes, o que requer uma administração.

Como exemplo de providência de natureza administrativa, geralmente necessárias, lembramos o recrutamento e a mobilização de 
pessoal, o seu treinamento ou aperfeiçoamento, contatos com entidades envolvidas, requisição de material e equipamento em quantidade e qualidade adequada para a investigação, cronogramas de controle de produção, quadros demonstrativos, organogramas, etc.

Em alguns países, existem instituições particulares e públicas que fornecem suporte administrativo ao desenvolvimento de pesquisas em enfermagem, aliado não raro a apoio financeiro. Em nosso meio, ainda estamos distantes dessa situação, o que leva à recomendação de ser oportuno o preparo em administração de pesquisa dos próprios profissionais de enfermagem; evidentemente, conhecimentos gerais de metodologia e investigação científica fornecem elementos para melhor direção de uma pesquisa.

Por outro lado, atualmente as pesquisas da área saúde, como já salientamos, não podem via de regra prescindir de uma abordagem multidisciplinar; conseqüentemente, os grupos de pesquisa costumam ser compostos de especialistas de diferentes áreas. Para BERLING (3), quanto ao pessoal que executa uma pesquisa, esta se classifica em individual e grupal, sendo que ela é tipicamente multidisciplinar. Muitas das pesquisas desenvolvidas pela enfermagem possuiam esta última característica.

A destacar, há o fato de que a divisão interna da investigação por áreas especializadas requer uma interrelação dos participantes; a falha de um dos membros do grupo pode comprometer os resultados da pesquisa como um todo, o que demonstra a importância de, em tais situações, existir uma administração perfeita da pesquisa. Esta se faz sentir não só na orientação e supervisão do grupo de trabalho, mas também no controle do desenvolvimento e avaliação de pesquisa.

Geralmente as tarefas administrativas são atribuídas a um coordenador, membro da equipe, e conhecedor de metodologia da investigação científica.

As pesquisas multidimensionais do campo da enfermagem, sem dúvida, deveriam ser coordenadas por um enfermeiro, que para ser um administrador eficiente necessita de conhecimentos sólidos de metodologia de pesquisa. 


\section{CONCLUSÃO}

Entendemos, pois, ser o conhecimento de metodologia de pesquisa uma necessidade atual. Evidentemente, nem todos os profissionais de enfermagem deverão ter o mesmo preparo; a estrutura e as características do seu treinamento subordinam-se às funções futuras esperadas de cada um. Assim, em alguns casos, treinamentos rápidos em cursos introdutórios, são suficientes; em outros, o treinamento, idealmente, deveria ser mais profundo no seu total ou em determinados módulos do processo de pesquisa. Ainda merece ser lembrada a conveniência da realização de cursos para a atualização em metodologia.

Em síntese, poder-se-ia dizer que conhecimento de metodologia de pesquisa é importante pelo fato de possibilitar leitura crítica de publicações, identificação de áreas de enfermagem que estão necessitando de investigação, empréstimo de apcio à produção de pesquisas em áreas problemáticas, obtenção de dados novos, correção de informações até então deficientes e/ou não científicas, aprimoramento do processo de administração e obtenção de financiamento.

O conhecimento focalizado, em última análise, pode colaborar na caracterização de enfermagem, como ciência.

WITT, A. - Why know research methodology. Rev. Esc. Enf. USP, 10 (3):340-348, 1976.

Here is presented the increasing need of nurses to learm the research methodology, and discused the utilization, making and management of research, related to the development of nursing as a science.

\section{BIBLIOGRAFIA}

1. ABRAMO, P. - Pesquisa em ciências sociais. São Paulo, ASESP, 1970. $78 \mathrm{p}$.

2. BAEZ, M. M. - El sanitarista como investigador. Higiene, 19 (6): 435-441, 1968. 
3. BERLING, M. T. - Palestra proferida em 27.4.76 no Seminário Ciência, Tecnologia e Pesquisador. Assoc. Agrôn. e APSS. SP.

4. DOBY, J. T. - An introduction to social research. $2 .^{\circ}$ nd. ed. New York, Appleton - Century - Crofts, 1967. 381 p.

5. GARO, I. G. - Approaches to evaluative research: a review Adm. Human Relation, 28: 8799-88, 91, 1969.

6. HORTA, W. A. - Editorial: pesquisa em enfermagem. Enf. Novas Dimens., 2(2): iii, 1976.

7. LANCASTER, A. - Towards a research based profession. Nurs. Times, 72(22): 632-633, jun. 1976.

8. POURCHET, M. A. C. - A investigação científica e as sociedades modernas. Palestra proferida na UFP em 29.6.1967.

9. RINEHART, J. M. - Learning the research process: one approach Nurs. Outlook, 21: 38-40, 1976.

10. SCHLOTFELD, R. M. - Research in nursing and research. Training; for nurses: retrospect and prospect. Nurs. Research, 24: 177$183,1975$. 